\title{
Trust in the referring physician reduces anxiety in an integrated community-to- hospital care system
}

\author{
Moshe Y. Flugelman ${ }^{1,2^{*}}$, Ronen Jaffe ${ }^{1,2}$, Gil Luria $^{3}$ and Dana Yagil ${ }^{3}$
}

\begin{abstract}
Background: Continuity of care between the community and hospital is considered of prime importance for quality of care and patient satisfaction, and for trust in the medical system. In a unique model of continuity of care, cardiologists at our hospital serve as primary, community-based cardiologists one day a week. They refer patients from the community to our hospital for interventional procedures such as coronary angiography and angioplasty. We examined the hypotheses that patient anxiety during hospital-based coronary angiography is lower when a patient trusts the referring cardiologist and when the performing cardiologist also treated him/her in the community.

Methods: We administered questionnaires to 64 patients in our cardiology department within 90 min of completion of coronary angiography. The questions assessed anxiety, trust in the medical system and trust in the referring physician. Data were also collected regarding patients' demographic variables, the number of visits to the referring physician, and whether the physician who performed the coronary angiography was the physician who referred the patient to the hospital.
\end{abstract}

Results: Mean levels (on 7-point Likert scales) were 2.1, 5.6 and 6.7 for patient anxiety, trust in the medical system and trust in the referring physician, respectively. Multivariate regression analysis showed that trust in the referring physician was significantly and negatively correlated with anxiety level. The number of visits to referring physicians, patients' demographic characteristics and whether the physician who performed the angiography was the same physician who referred the patient from the community were not found to be associated with patient anxiety.

Conclusion: In this study, trusting the referring physician was associated with lower anxiety among patients who underwent coronary angiography. This trust seemed to have more positive impact than did previous contact with the physician who performed the procedure.

Keywords: Continuity of care, Trust, Anxiety, Hospitalization

\section{Background}

Continuity of care has been identified as a major component of high-quality care and of patients' satisfaction [14]. Continuity of care between community and hospital settings is particularly challenging, as it involves bilateral transfer of information and coordination over time. Fragmentation of care can reduce patients' trust in the

\footnotetext{
* Correspondence: myf@technion.ac.il

'Department of Cardiovascular Medicine, Lady Davis Carmel Medical Center,

7 Michal Street, 34632 Haifa, Israel

${ }^{2}$ Rappaport Faculty of Medicine, Technion Israel Institute of Technology,

Haifa, Israel

Full list of author information is available at the end of the article
}

medical system and in physicians, and increase anxiety prior to interventions in an unfamiliar setting such as hospitals [5-10]. Moreover, a number of models of encounters between patients and previously unknown physicians have highlighted the impact of trust between the physician and the patient on reducing anxiety $[11,12]$.

Over the last three decades, we have employed a unique model for continuity of care for cardiology [5, 13]. Hospital-based cardiologists serve as primary, community-based cardiologists one day a week. They refer their patients in the community to our hospital for interventional procedures such as coronary angiography 
and angioplasty. Indications for coronary angiography are re-evaluated in the hospital, and if confirmed, patients undergo the procedure. If the referring cardiologist is an interventional cardiologist, we try to arrange that this cardiologist will perform the angiography and angioplasty for the patient he/she referred from the community.

Based on our continuity of care model, we examined the hypotheses that patient anxiety during hospitalbased coronary angiography is lower when a patient trusts the referring cardiologist, and when the performing cardiologist also treated him/her in the community. To test our hypotheses, we interviewed patients who underwent coronary angiography and angioplasty, regarding their level of anxiety, their trust in the medical system, and their trust in the physician who referred them. We compared responses between patients according to whether the cardiologist who referred them also performed the coronary angiography and angioplasty.

\section{Methods}

\section{Participants}

The sample consisted of 64 patients in the Department of Cardiovascular Medicine who had undergone coronary angiography and angioplasty. Fifty-six (88\%) of the patients reported the number of visits they had in the community with the physician who referred them to the procedure; $29 \%$ reported one visit, $36 \%$ two visits, $21 \%$ three visits and $14 \%$ reported four visits or more.

Inclusion criteria were referral to elective coronary angiography, and the capability and willingness to participate in the study. Patients with acute coronary syndromes were excluded from the study.

\section{Procedure}

The institutional review board of Lady Davis Carmel Medical Center waived the need for approval of this study. Hospitalized patients who were after coronary angiography were asked to participate in the study. There were no refusals to participate. Patients with unstable medical conditions were not approached regarding participation. Interviewers were conducted by senior nursing students who received particular training for this study and who were introduced to the nursing staff at the catheterization inpatient unit. Since questionnaires were in Hebrew, the interviewers translated the questionnaires to patients who needed translation or clarification in additional languages (Arabic and Russian). As the interviewers speak Hebrew and at least one additional language, the use of an external translator was infrequent. Questionnaires were administered to respondents by the interviewers within $90 \mathrm{~min}$ of completion of coronary angiography and angioplasty.

\section{Measures}

State anxiety was measured with 13-items from the Trait Anxiety Inventory (STAI) [14], which was previously used to measure cardiac patients' anxiety [15]. An example item is: "I feel tense". Participants were asked to indicate on a 7-point Likert scale $(1=$ "not at all"; $7=$ "very much") their feelings at the moment. Cronbach's alpha reliability was 0.87 .

Trust in the medical system was measured with a 4-item scale [16]. An example item is: "To what extant do you believe that the medical system puts your medical needs above all other matters?" Participants were asked to respond according to a 7 -point Likert scale $(1=$ "not at all"; 7 = "very much"). Cronbach's alpha reliability was 0.66 .

Trust in the physician who referred the patient to catheterization was measured with a 5-item scale [16]. An example item is: "To what extent do you believe your doctor chose the best medical treatment for you?" Participants were asked to respond according to a 7-point Likert scale ( $1=$ "not at all"; $7=$ "very much"). Cronbach's alpha reliability was 0.63 .

Demographic characteristics and medical encounter details were accessed from the patients: age, education, the number of visits to the physician who referred them to catheterization, and whether the physician who referred them also performed the procedure.

Self-efficacy, meaning that a person feels capable of accomplishing tasks [17], was also assessed using our questionnaire. Scoring was according to a 7-point Likert scale (1 $=$ "not at all"; 7 = "a very high level of self-efficacy").

\section{Statistical analysis}

To predict patients' anxiety, we conducted a multiple linear regression analysis. Independent variables were entered in three phases to evaluate their distinct contributions. Demographic variables (i.e., gender, age and education) were entered in the first phase. The number of visits to the physician and whether the physician who referred them to catheterization also performed the procedure were entered in the second phase. Trust in the medical system and trust in the physician who referred the patient were entered in the third phase.

To examine the association of the familiarity of the referring physician with patient anxiety we conducted a one-way analysis of variance. We used SPSS 21 version for statistical analysis.

\section{Results}

Fifty-two (81\%) of the patients reported the identity of the physician who referred them to the procedure. Seventeen $(27 \%)$ reported that the physician who referred them was the same physician who performed the procedure, $24(38 \%)$ reported being referred by a physician who works in the hospital where the procedure 
was performed and $11(17 \%)$ were referred by another physician. Means and standard deviations of the variables examined, and correlations between them are shown in Table 1 . The mean age of the respondents was 66.8 years $(S D=10.8)$, their mean years of education was $13.1(S D=2.75)$; $45(70 \%)$ were men.

Mean levels (on 7-point Likert scales) for patient anxiety, trust in the medical system and trust in the physician were 2.1, 5.6 and 6.7, respectively. Significant inverse correlations were observed between anxiety and trust in the physician, and between anxiety and trust in the system. Scores on self-efficacy did not differ between the groups.

We conducted a multiple linear regression analysis of the variables that were associated with anxiety (Table 2), using the three stages detailed in the statistical methods section. The results of this analysis indicated that trust in the referring physician was negatively related to anxiety, beyond the effect of the other variables.

Anxiety level was similar between the patient groups, according to the patient's relation with the performing physician. For patients for whom the physician who referred them to angiography was the same physician who performed the procedure, the mean value was $2.09 \pm 0.9$ (Table 3). For patients who were referred by a physician who works in the hospital where the procedure was performed, the mean value was $2.19 \pm 0.7$. For patients who were referred by another physician, the mean value was $1.92 \pm 0.6$ (Table 3).

\section{Discussion}

Our findings supported our hypothesis of an inverse association of patient anxiety with trust in the referring cardiologist. However, the findings do not support our hypothesis of higher trust and lower anxiety among patients for whom the cardiologist who performed the intervention had referred him/her. Rather, trust in the referring physician was a stronger determinant of anxiety than was the prior relationship of the patient with the physician who performed the angiography. Trust in the

Table 1 Means, standard deviations and correlations of the variables investigated

\begin{tabular}{|c|c|c|c|c|c|c|}
\hline & $\begin{array}{l}\text { Mean (standard } \\
\text { deviation) }\end{array}$ & 1 & 2 & 3 & 4 & 5 \\
\hline 1.Anxiety & $2.0(.73)$ & & & & & \\
\hline $\begin{array}{l}\text { 2.Trust in the } \\
\text { medical system }\end{array}$ & $5.58(1.41)$ & $-.28^{*}$ & & & & \\
\hline $\begin{array}{l}\text { 3.Trust in the } \\
\text { physician }\end{array}$ & $6.66(.60)$ & $-.59^{* *}$ & $.31^{*}$ & & & \\
\hline 4.Number of visits & & .25 & .09 & .08 & & \\
\hline 5.Age & $66.84(10.09)$ & -.03 & -.04 & .06 & -.04 & \\
\hline 6.Education & $13.06(2.95)$ & -.05 & -.21 & .08 & -.02 & -.06 \\
\hline
\end{tabular}

${ }^{*} p<.05 ;{ }^{* *} p<.01$
Table 2 Regression analysis of various factors (demographic factors, medical encounter details, and trust in the system and in the physician) on patient anxiety

\begin{tabular}{|c|c|c|c|c|c|c|c|c|c|}
\hline \multirow[t]{2}{*}{ Variable 3} & \multicolumn{3}{|c|}{ Phase 1} & \multicolumn{3}{|c|}{ Phase 2} & \multicolumn{3}{|c|}{ Phase 3} \\
\hline & $B$ & $\begin{array}{l}S E \\
(B)\end{array}$ & B & B & $\begin{array}{l}S E \\
(B)\end{array}$ & $\beta$ & B & $\begin{array}{l}S E \\
(B)\end{array}$ & $\beta$ \\
\hline Gender & .28 & .21 & .20 & .27 & .22 & .20 & .28 & .20 & .21 \\
\hline Age & .01 & .01 & .20 & .01 & .01 & .18 & .01 & .01 & .19 \\
\hline Education & .00 & .03 & .03 & .00 & .00 & .03 & .00 & .03 & .03 \\
\hline Number of visits & & & & .02 & .06 & .05 & .05 & .06 & .13 \\
\hline $\begin{array}{l}\text { Referring physician } \\
\text { performed/did not } \\
\text { perform the procedure }\end{array}$ & & & & .09 & .13 & .11 & .07 & .12 & .09 \\
\hline $\begin{array}{l}\text { Trust in the medical } \\
\text { system }\end{array}$ & & & & & & & -.10 & .07 & -.23 \\
\hline Trust in the physician & & & & & & & -.37 & .18 & $-.31^{*}$ \\
\hline$R^{2}$ & & & .07 & & & .09 & & & .26 \\
\hline$F$ & & & .99 & & & .69 & & & 1.75 \\
\hline
\end{tabular}

physician was also a stronger determinant of anxiety than any of the demographic characteristics examined. Our findings suggest that the "holy grail" of reducing patient anxiety during hospitalization does not entail being treated by the same physician as in the community, but rather, trusting the referring physician regardless as to whether $\mathrm{s} /$ he performed the procedure in the hospital.

The components that instill trust are detailed by Bachrach et al. in the seven dimensions' model of continuity

Table 3 Patients' attitudes toward physicians and the medical system, according to familiarity with the catheterizing physician $1.92 \pm 0.6$

\begin{tabular}{lllll}
\hline Variable & $\begin{array}{l}\text { Catheterizing } \\
\text { physician }\end{array}$ & $\begin{array}{l}\text { Number of } \\
\text { patients }\end{array}$ & $\begin{array}{l}\text { Mean } \pm \\
\text { SD }\end{array}$ & $\begin{array}{l}p \\
\text { Value }\end{array}$ \\
\hline Anxiety & Referring & 17 & $2.09 \pm 0.9$ & NS \\
& Non referring & 24 & $1.92 \pm 0.6$ & \\
& Same department & 11 & $2.19 \pm 0.7$ & \\
Satisfaction & Referring & 17 & $6.4 \pm 0.7$ & NS \\
with the & Non referring & 22 & $6.4 \pm 0.9$ & \\
physician & Same department & 10 & $6.0 \pm 0.8$ & \\
& Referring & 17 & $6.6 \pm 0.8$ & NS \\
Trust in the & Non referring & 24 & $6.8 \pm 0.5$ & \\
physician & Same department & 11 & $6.6 \pm 0.6$ & \\
& Referring & 17 & $5.14 \pm 1.7$ & NS \\
Trust in the & Non referring & 24 & $5.66 \pm 1.5$ & \\
system & Same department & 11 & $5.63 \pm .83$ & \\
& Referring & 16 & $6.4 \pm 1.0$ & NS \\
Self-efficacy & Non referring & 24 & $6.8 \pm 0.5$ & \\
& Same department & 11 & $6.8 \pm 0.4$ & \\
\hline
\end{tabular}


of care [9]. Hennen described four dimensions of continuity of care in family practice: chronological, geographical, interdisciplinary and interpersonal [18]. In agreement, our work suggests that trust can be generated despite differences in geography and in disciplines, and despite treatment by unfamiliar physicians.

Findings similar to ours were described by Hinnen et al., who showed an association between lower trust in one's physician and higher rates of distress among patients with cancer who had attachment anxiety [19]. Moreover, the inverse association between anxiety and empathic response from a physician was shown in a study on hospital admissions. There, the frequency of empathic responses by the physicians was associated with trust and with the perception of being cared by the physician [20].

Contrary to our expectations, our data did not support a substantial role of relational continuity in the level of anxiety during hospitalization. Rather, our data showed low anxiety overall. We presume that the high quality of care of our system, and the high level of trust that our patients attribute to their referring physicians may help overcome gaps between the community and hospital, and thus reduce patients' anxiety. The literature is inconclusive regarding associations of healthcare continuity with patients' satisfaction and with quality of healthcare. Accordingly, one systematic review found a variable effect of continuity on patients' satisfaction [21], while a more recent meta-analysis showed reduced mortality with continuity of care [22].

There are several limitations to our study. These include the relatively small sample size and the timing of the interviews, which were conducted after completion of a medical procedure. While the latter may have affected our findings, the administration of diazepam as pre-procedural medication to all the patients precluded conducting the interviews prior to the procedure. The high levels of patient satisfaction may hinder our capacity to detect differences between patients according to familiarity with hospital physicians, and Cronbach's alpha reliability was of borderline level in this study. Based on the abovementioned issues, our findings should be regarded as preliminary, and a larger scale study should be considered.

\section{Conclusions}

This study showed that trust in the referring physician is a strong determinant of lower anxiety during procedures in the hospital. This trust was independent of the familiarity of the patient with the physician who performed the procedure. Our findings merit additional studies with a larger number of patients to examine the association between patients' trust and anxiety in various settings.

\author{
Acknowledgements \\ None. \\ Authors' contributions \\ Moshe Y. Flugelman, MD initiated the project, and participated in planning, \\ analyzing the data and writing the manuscript. Ronen Jaffe, MD, participated \\ in planning and enabling the project, and reviewed the data and the \\ manuscript. Gil Luria, PhD, participated in developing the methodology of \\ the study, analyzing the data and reviewing the manuscript. Dana Yagil, PhD, \\ participated in formulating the hypothesis, leading the development of the \\ methodology, analyzing the data and writing the manuscript.
}

\section{Authors' information}

Moshe Y. Flugelman, MD, Director, Department of Cardiovascular Medicine, Lady Davis Carmel Medical Center, Professor of Medicine and Vice Dean for Education, Rappaport Faculty of Medicine, Technion, IIT, Haifa, Israel. Ronen Jaffe, MD, Director, Catheterization laboratory, Department of Cardiovascular Medicine, Lady Davis Carmel Medical Center, Associate Clinical Professor of Medicine, Rappaport Faculty of Medicine, Technion, IIT, Haifa, Israel.

Gil Luria, PhD, Associate professor, Department of Human Services, University of Haifa, Haifa, Israel.

Dana Yagil, PhD, Associate professor, Department of Human Services, University of Haifa, Haifa, Israel.

\section{Funding}

There are no funding resources.

Availability of data and materials

Data are available upon request.

\section{Ethics approval and consent to participate}

The institutional review board of Lady Davis Carmel Medical Center waived the need for approval of this study. Hospitalized patients before coronary angiography were asked to participate.

\section{Consent for publication}

All authors reviewed the manuscript and consented to its publication.

\section{Competing interests}

The authors declare that they have no competing interests.

\section{Author details}

${ }^{1}$ Department of Cardiovascular Medicine, Lady Davis Carmel Medical Center, 7 Michal Street, 34632 Haifa, Israel. ${ }^{2}$ Rappaport Faculty of Medicine, Technion Israel Institute of Technology, Haifa, Israel. ${ }^{3}$ Department of Human Services, University of Haifa, Haifa, Israel.

Received: 28 September 2019 Accepted: 10 February 2020

Published online: 11 May 2020

\section{References}

1. Freeman GK, Olesen F, Hjortdahl P. Continuity of care: an essential element of modern general practice? Fam Pract. 2003;20:623-7.

2. Saultz JW, Lochner J. Interpersonal continuity of care and care outcomes: a critical review. Ann Fam Med. 2005;3:159-66.

3. Christakis DA. Continuity of care: process or outcome? Ann Fam Med. 2003; 1:131-3.

4. Gulliford M, Naithani S, Morgan M. What is 'continuity of care'? J Health Serv Res Policy. 2006;11:248-50.

5. Flugelman AA, Baharir Z, Lewis BS, et al. An integrated model of cardiological consultation and primary care medicine. Br J Gen Pract. 1990; 40:259.

6. Haggerty JL, Reid RJ. Freeman GK, et al. Continuity Care. 2003;327:1219-21

7. Bachrach LL. Continuity of care for chronic mental patients: a conceptual analysis. Am J Psychiatry. 1981;138:1449-56.

8. Bayliss EA, Ellis JL, Shoup JA, et al. Effect of continuity of care on hospital utilization for seniors with multiple medical conditions in an integrated health care system. Ann Fam Med. 2015;13:123-9. 
9. Sharma G, Fletcher KE, Zhang D, et al. Continuity of outpatient and inpatient care by primary care physicians for hospitalized older adults. JAMA. 2009;301:1671-80.

10. Cowie L, Morgan M, White P, Gulliford MJ. Experience of continuity of care of patients with multiple long-term conditions. England Health Serv Res Policy. 2009;14:82-7.

11. Dand BN, Westbrook RA, Njue SM, Giordano TP. Building trust and rapport early in the new doctor-patient relationship: a longitudinal qualitative study. BMC Medical Education. 2017;17:32-42.

12. Zwingmann J, Baile WF, Schmier JW, Bernhard J, Keller M. Effects of patientcentered communication on anxiety, negative affect, and trust in the physician in delivering a cacner diagnosis: a randomized, experimental study. Cancer. 2017;123:3167-75.

13. The Story of Clalit Health Services. http://clalit-global.co.il/en/_the_story_of_ clalit health services.html. Accessed Jan. 302020

14. Spielberger CD, Gorsuch RL, Lushene R, et al. Manual for the state-trait anxiety inventory. Palo Alto: Consulting Psychologists Press; 1983.

15. Hughes JW, Tomlinson A, Blumenthal JA, et al. Social support and religiosity as coping strategies for anxiety in hospitalized cardiac patients. Ann Behav Med. 2004:28:179-85.

16. Gordon HS, Pugach O, Berbaum ML, et al. Examining patients' trust in physicians and the VA healthcare system in a prospective cohort followed for six-months after an exacerbation of heart failure. Patient Educ Couns. 2014;97:173-9.

17. Bandura A. Self-efficacy: toward a unifying theory of behavior change. Psychol Rev. 1977:84:191-215.

18. Hennen BK. Continuity of care in family practice. Part 1: dimensions of continuity. J Fam Pract. 1975;2:371-2.

19. Hinnen C, Pool G, Holwerda N, Sprangers M, Sanderman R, Hagedoorn M. Lower levels of trust in one's physician is associated with more distress over time in more anxiously attached individuals with cancer. Gen Hosp Psychiatry. 2014;36:382-7.

20. Weiss R, Vittinghoff E, Fang MC, Cimino JEW, Chasteen KA, Arnold RM, Auerbach AD, Anderson WG. Association of physician empathy with patient anxiety and rating of communication in hospital admission encounters. J Hosp Med. 2017;12:805-10

21. Adler R, Vasiliadis A, Bickell N. The relationship between continuity and patient satisfaction: a systematic review. Fam Pract. 2010;27:171-8.

22. Pereira Gray DJ, Sidaway-Lee K, White E, Thorne A, Evans PH. Continuity of care with doctors - a matter of life and death? A systematic review of continuity of care and mortality. BMJ Open. 2018;8:e021161.

\section{Publisher's Note}

Springer Nature remains neutral with regard to jurisdictional claims in published maps and institutional affiliations.

Ready to submit your research? Choose BMC and benefit from:

- fast, convenient online submission

- thorough peer review by experienced researchers in your field

- rapid publication on acceptance

- support for research data, including large and complex data types

- gold Open Access which fosters wider collaboration and increased citations

- maximum visibility for your research: over $100 \mathrm{M}$ website views per year

At $\mathrm{BMC}$, research is always in progress.

Learn more biomedcentral.com/submissions 